\title{
Edukasi Pencegahan Anemia Remaja Putri Pada Orang Tua dan Guru Santri Madrasah
}

\author{
*Apriningsih", Dian Lutfiana Sufyan ${ }^{2)}$ \\ ${ }^{1)}$ Prodi S1-Kesehatan Masyarakat, FIKES, Universitas Pembangunan Nasional Veteran Jakarta \\ ${ }^{2)}$ Prodi S1-Ilmu Gizi, FIKES, Universitas Pembangunan Nasional Veteran Jakarta
}

Correspondece author: Apriningsih,apriningsih@upnvj.ac.id

Received : 20 Agustus $2021 \quad$ Accepted : 24 September 2021

Published: 30 September 2021

DOI: https://doi.org/10.37012/jpkmht.v3i2.720

\begin{abstract}
ABSTRAK
Angka prevalensi anemia pada remaja di Indonesia mengalami peningkatan dan dimasa mendatang berdampak terhadap kesehatan ibu hamil, dan kejadian stunting. Program pencegahan dan pengendalian anemia berbasis sekolah/ madrasah membutuhkan peran aktif berbagai pihak termasuk guru dan orang tua siswi. Oleh sebab itu perlu dilakukan edukasi kepada orang tua dan guru agar mereka dapat menjadi faktor pendorong perubahan perilaku siswi dalam mencegah dan mengendalikan anemia. Kegiatan pengabdian masyarakat yang berupa edukasi kesehatan secara virtual kepada orang tua dan guru madrasah Mumtaza Islamic School bertujuan untuk meningkatkan pengetahuan, sikap dan efikasi diri orang tua dan guru dalam program pencegahan dan pengendalian anemia pada remaja putri di lingkungan madrasah. Harapannya program ini dapat turut andil dalam mempromosikan program penurunan kasus anemia remaja putri dan meningkatkan status gizi siswi madrasah.Setelah diadakan edukasi kesehatan terdapat perbedaan tingkat pengetahuan, sikap dan efikasi diri orang tua dan guru terhadap program pencegahan dan pengendalian anemia pada remaja putri $(\mathrm{p}<0.005)$.
\end{abstract}

Kata Kunci: Anemia,Edukasi Kesehatan,Guru, Orang Tua, Remaja Putri.

\begin{abstract}
The prevalence of anemia in adolescents in Indonesia has increased and in the future, it will have an impact on the health of pregnant women, and the incidence of stunting. School-based anemia prevention and controlling program require the active role of various parties including teachers and parents of students. Therefore it is necessary to educate parents and teachers so that they can be a driving factor for changes in student behavior in preventing and controlling anemia. Community service activities in the form of online health education to parents and madrasah teachers at Mumtaza Islamic school aim to improve the knowledge, attitudes and self-efficacy of parents and teachers in the prevention and control program of anemia in adolescent girls in the madrasa environment. It is hoped that this program can contribute to promoting the program for reducing anemia in adolescent girls and improving the nutritional status of madrasah students. After health education was held, there were differences in the level of knowledge, attitudes and self-efficacy of parents and teachers towards the anemia prevention and control program in adolescent girls. $(p<0.005)$
\end{abstract}

Keywords: Anaemia,Health Education,Parents, Teachers, Female Adolescent. 


\section{PENDAHULUAN}

Salah satu masalah gizi global yang masih perlu diatasi karena berdampak terhadap kesehatan manusia, dan juga status sosial ekonomi adalah anemia pada remaja putri. Prevalensi anemia pada remaja (kelompok usia 18-24tahun) di Indonesia mengalami kenaikan dari 18,24\% pada tahun 2013 menjadi 32\% pada tahun. Proporsi anemia pada perempuan lebih besar (27,2\%) daripada pada laki-laki (20,3\%)(Kementerian Kesehatan RI Badan Penelitian dan Pengembangan Kesehatan, 2019).

Anemia gizi besi terjadi di antaranya karena kurangnya asupan makanan yang mengandung sumber zat besi. Hasil studi di Tangerang pada tahun 2004 memperlihatkan asupan total zat besi pada anak perempuan penderita anemia umur 10-12 tahun hanya sebesar 5,4 mg/hari, lebih rendah dari kebutuhan per hari sebesar $20 \mathrm{mg} / \mathrm{hari}$ sesuai Angka Kecukupan Gizi 2013(Kemenkes RI, 2016). Kementerian Kesehatan menargetkan pengurangan prevalensi anemia kurang dari $20 \%$ bagi remaja dan menargetkan sebanyak $30 \%$ remaja putri mendapatkan Tablet Tambah Darah (TTD) (Kementerian Kesehatan RI 2015). Hal ini menjadi salah satu dari strategi yang pemerintah lakukan dalam menangani kasus anemia pada remaja putri.

Program pemberian TTD sepekan sekali berbasis sekolah menjadi salah satu program pencegahan dan penanggulangan anemia pada remaja putri di dunia termasuk di Indonesia. Data Riskesdas 2018 menunjukkan angka cakupan pemberian TTD yang tinggi $(80,9 \%)$ tidak dibarengi dengan angka kepatuhan minum tablet tambah darah yang tinggi pula pada remaja putri berbasis sekolah, hanya 1,4\% remaja putri yang mengonsumsi TTD sesuai anjuran yaitu 52 tablet per tahun(Kementerian Kesehatan RI Badan Penelitian dan Pengembangan Kesehatan, 2019).

Rendahnya angka konsumsi TTD pada siswi sekolah ini disebabkan beberapa faktor yaitu usia, pengetahuan, sikap, dan efikasi diri, pernah periksa $\mathrm{Hb}$ sebelumnya, sekolah mengadakan minum TTD bersama sepekan sekali dan guru mengedukasi siswa tentang manfaat TTD bagi siswi (Apriningsih et al., 2020). Studi yang dilakukan Apriningsih et.al., di Kota Depok menemukan bahwa orang tua berperan dalam meningkatkan kepatuhan minum TTD pada remaja putri, beberapa sekolah juga melaporkan adanya larangan dari orang tua kepada anaknya untuk mengonsumsi TTD karena khawatir ada efek sampingnya (Apriningsih et al., 2019). Model sosial ekologi juga menyatakan pentingnya peranan orang tua dan guru dalam memengaruhi perilaku anak, selain teman sebaya dan faktor internal remaja putri itu sendiri (Contento, 2011). Oleh sebab itu kegiatan pengabdian masyarakat ini menargetkan 
orang tua dan guru sebagai sasaran edukasi kesehatan agar dapat memotivasi dan meningkatkan kepatuhan minum TTD pada remaja putri.

Seperti siswi sekolah umum, santri madrasah juga merupakan remaja putri yang rentan menderita anemia remaja putri. Program pemberian tablet tambah darah (TTD) merupakan salah satu program penyelenggaraan Usaha Kesehatan Sekolah/Madrasah (UKS/M) yaitu bagian dari pelaksanaan pelayanan kesehatan yang bertujuan mencegah dan mengendalikan prevalensi anemia pada remaja putri termasuk pada santri madrasah. Madrasah Mumtaza Islamic School yang berlokasi di Tangerang Selatan, memiliki cukup banyak santri yang sudah mengalami menstruasi, dan selama ini belum pernah ada sosialisasi dan edukasi kesehatan terkait pencegahan dan penanggulangan anemia pada remaja putri baik pada santri, guru maupun orang tua. Dengan demikian pemberian edukasi kesehatan ini diperlukan oleh para orang tua dan guru agar dapat berperan lebih banyak dalam memotivasi dan memelihara status gizi putrinya. Situasi pandemic menyebabkan pemberian edukasi kesehatan yang dilakukan menggunakan virtual zoom meeting.

\section{METODE PELAKSANAAN}

Metode pelaksanaan kegiatan pengabdian kepada masyarakat yang diadakan di madrasah mumtaza Islamic school dilakukan melalui 3 tahapan, yaitu melakukan analisis situasi masalah yang dihadapi mitra sekolah, melakukan persiapan penyelenggaran edukasi kesehatan, dan penyelenggaraan edukasi kesehatan. Analisis kesehatan dilakukan dengan melakukan studi kepustakaan dan wawancara dengan beberapa orang tua santri. Selanjutnya dilakukan koordinasi dengan parent teacher association (PTA) untuk menentukan waktu dan teknis kegiatan edukasi.

Kegiatan edukasi kesehatan diselenggarakan selama satu hari menggunakan zoom meeting. Sebelum diberikan edukasi panitia mendistribusikan kuesioner online menggunakan google form (pre test) untuk di isi oleh para peserta. Pada akhir sesi edukasi peserta diminta mengisi kembali google form (post test). Hal ini untuk mengukur efektivitas edukasi yang diberikan dengan menganalisis perbedaan tingkat pengetahuan, sikap dan efikasi diri peserta dalam program pencegahan dan pengendalian anemia pada remaja putri. Peserta juga dimintakan pendapat dan saran masukan untuk mengevaluasi pelaksanaan edukasi kesehatan dan perbaikan kegiatan pengabdian masyarakat di masa mendatang. 


\section{HASIL DAN PEMBAHASAN}

Deskripsi Kegiatan Edukasi Kesehatan pada Orang tua dan Guru Santri Madrasah Mumtaza Islamic School

Kegiatan pengabdian masyarakat yang dilakukan berupa edukasi kesehatan kepada orang tua dan guru santri madrasah Mumtaza isamic School. Kegiatan ini bertujuan untuk meningkatkan pengetahuan, sikap dan efikasi diri orang tua dan guru santri tentang pencegahan dan pengendalian anemia remaja putri sehingga orang tua dapat memotivasi dan menjadi pendamping bagi putrinya untuk mengonsumsi makanan sumber zat besi dan meningkatkan kepatuhan minum TTD. Hal ini didasarkan pada teori social ecological model yang menyatakan bahwa orang tua dan guru berperan penting dalam perilaku dan status kesehatan individu (Contento, 2011). Aditianti et.al., 2015 juga menyatakan bahwa kepatuhan minum TTD dapat meningkat disebabkan adanya pemberian penyuluhan kepada pendamping. Kegiatan edukasi kesehatan berlangsung secara virtual pada hari kamis tanggal 7 Oktober 2021 dengan dihadiri sebanyak 75 peserta gabungan orang tua dan guru madrasah Mumtaza Islamic School menggunakan aplikasi zoom meeting. Madrasah Mumtaza Islamic School menerapkan sistem pembelajaran tatap muka terbatas, oleh karena kegiatan ini mengumpulkan banyak peserta maka kegiatan edukasi kesehatan ini menggunakan aplikasi zoom meeting. Berikut ini adalah tangkapan layar kegiatannya.

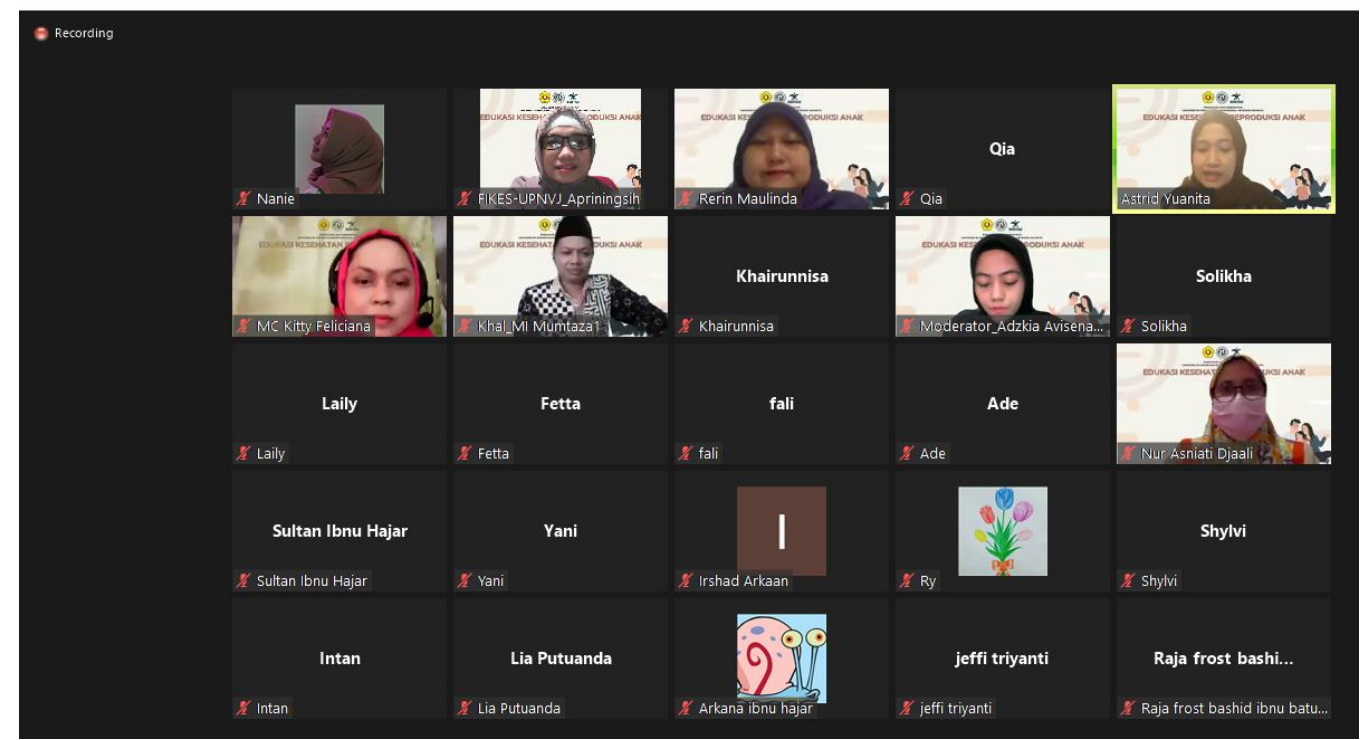

Gambar 1: Tangkapan layar kegiatan edukasi kesehatan virtual 


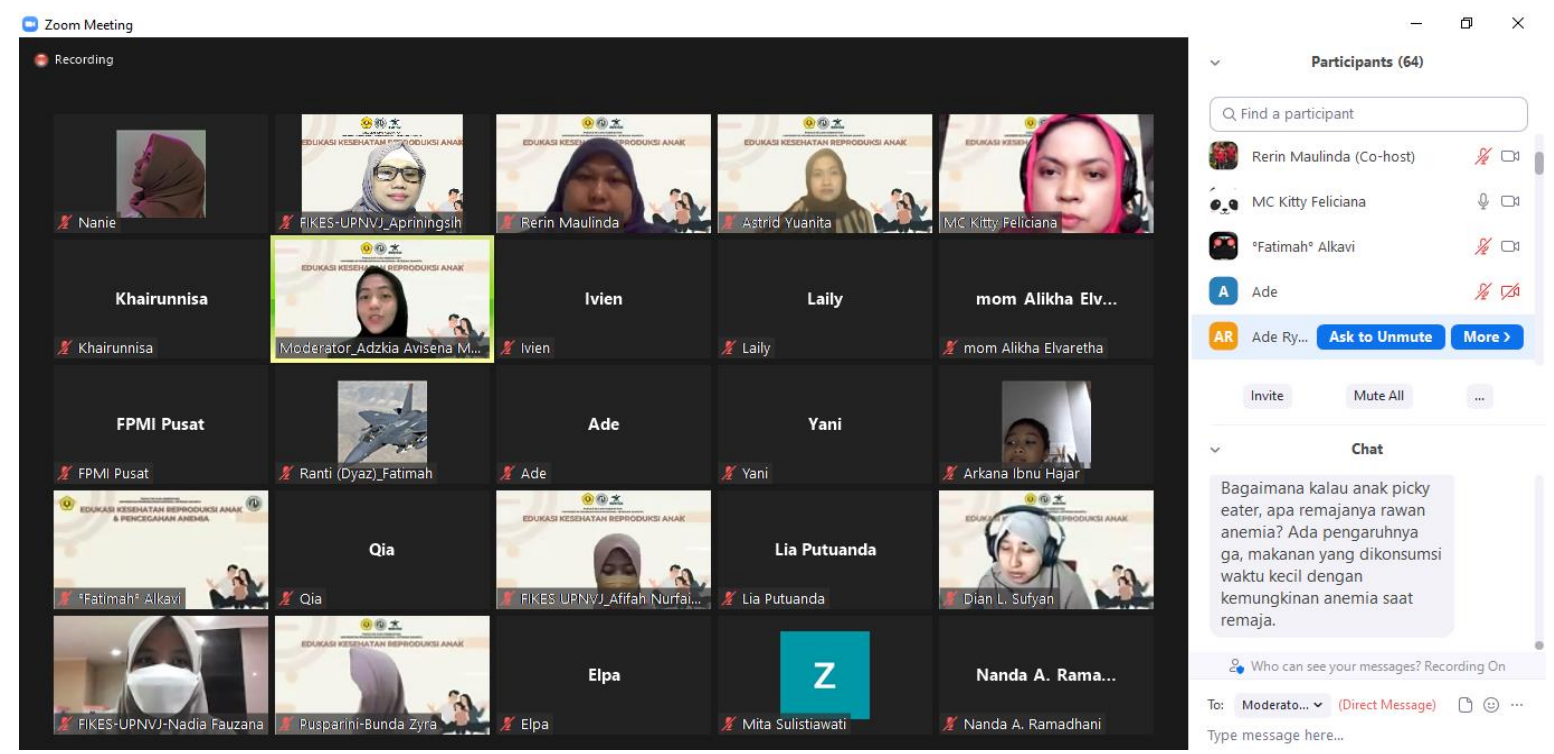

Gambar 2. Tangkapan layar tanya jawab materi edukasi

Kegiatan edukasi kesehatan mendapatkan apreasiasi yang baik dari Kepala Madrasah (KaMad) Madrasah dan ketua persatuan orang tua dan guru Mumtaza Islamic School. Madrasah ini memiliki 3 jenjang pendidikan yaitu Radiatul Anfal setingkat taman kanakkanak (TK) yang berlokasi di Bukit Raya Cirendeu, Pisangan Ciputat, Madrasah Ibtidaiyah setingkat sekolah dasar (SD) dan Madrasah Tsanawiyah setingkat SMP berlokasi di Jl.Kayu manis, Pondok Cabe, Udik, Tangerang. Sebagian besar peserta adalah guru dan orang tua dari madrasah tingkat ibtidaiyah.

Ketua persatuan orang tua dan guru menyampaikan ucapan terimakasih atas terselenggaranya edukasi kesehatan ini dan menilai acaranya bermanfaat bagi pihak sekolah dan juga bagi orang tua, karena santri kelas empat sudah banyak yang memasuki masa baligh dan mengalami menarche. Peserta sangat mengharapkan kegiatan edukasi kesehatan ini dapat dilanjutkan dimasa yang akan datang.

\section{Karakteristik Peserta Edukasi Kesehatan}

Peserta edukasi kesehatan dihadiri oleh 75 peserta gabungan orang tua dan guru santri madrasah Mumtaza Islamic School, namun yang mengisi google form pre test dan post test hanya 33 orang. Tabel 1 menampilkan karakteristik 33 peserta kelas edukasi virtual tentang pencegahan dan pengendalian anemia pada remaja putri yang diselenggarakan pada hari kamis, 7 Oktober 2021. 
Tabel 1.

Karakteristik Peserta Kelas Edukasi Virtual

\begin{tabular}{|c|c|c|}
\hline Karakteristik Orang tua & $\mathbf{n}$ & $\%$ \\
\hline \multicolumn{3}{|c|}{$\begin{array}{l}\text { Pengalaman mendapatkan sosialisasi tentang anemia remaja putri } \\
\text { dan manfaat TTD }\end{array}$} \\
\hline - Pernah & 10 & 30 \\
\hline - Tidak pernah & 23 & 70 \\
\hline \multicolumn{3}{|l|}{ Sumber informasi tentang anemia dan TTD } \\
\hline - Internet & 22 & 67 \\
\hline - Tenaga Kesehatan & 7 & 21 \\
\hline - Sekolah/guru & 4 & 12 \\
\hline \multicolumn{3}{|l|}{ Penilaian orang tua terhadap status anemia putrinya } \\
\hline - Putri saya kekurangan zat besi & 3 & 9.1 \\
\hline - Zat besi dalam tubuh putri saya sudah cukup & 6 & 18.2 \\
\hline - Putri saya tidak punya masalah kekurangan zat besi & 1 & 3.0 \\
\hline $\begin{array}{l}\text { - Kandunganzat besi dalam tubuh putri saya lebih dari ideal } \\
\text { - } \quad \text { Tidak Tahu }\end{array}$ & 18 & 54.5 \\
\hline \multicolumn{3}{|l|}{ Pendidikan terakhir orang tua } \\
\hline - SMA & 1 & 3.0 \\
\hline - $\mathrm{PT}$ & 30 & 97.0 \\
\hline \multicolumn{3}{|l|}{ Jenis kelamin } \\
\hline - -Perempuan & 28 & 85 \\
\hline - -Laki-laki & 5 & 15 \\
\hline Total & 33 & 100 \\
\hline
\end{tabular}

Sebagian besar peserta adalah perempuan, berlatar pendidikan perguruan tinggi dan belum pernah mendapatkan sosialisasi tentang anemia remaja putri dan manfaat TTD, sehingga materi ini menarik perhatian peserta. Mayoritas peserta menyatakan mendapatkan informasi anemia dan TTD dari internet. Oleh sebab itu kelas kegiatan edukasi yang melibatkan secara langsung nara sumber kesehatan dan bisa berdiskusi langsung sangatlah disambut positif oleh peserta.

Mayoritas peserta menjawab tidak mengetahui apakah putrinya menderita anemia atau tidak. Hal ini menunjukkan bahwa diagnose anemia dengan melihat gejala yang dialami yang dikanal dengan 5L (Letih, Lemah, Lesu, Lelah, Lunglai) belum diketahui oleh para peserta. Hal ini memperkuat landasan perlunya diadakan edukasi kesehatan tentang anemia pada remaja putri dan manfaat minum TTD.

Pengukuran pengetahuan, sikap dan efikasi diri guru dan orang tua santri Madrasah Mumtaza Islamic School

Efektivitas kegiatan edukasi kesehatan dievaluasi dengan mengukur tingkat pengetahuan, sikap dan efikasi diri orang tua dan guru santri madrasah saat sebelum kegiatan dan setelah kegiatan. Pada tabel 2 terlihat perbedaan secara signifikan antara tingkat pengetahuan, sikap dan efikasi diri 33 peserta sebelum dan setelah kelas edukasi kesehatan virtual $(\mathrm{P}<0.05)$. Hasil 
ini menunjukkan kegiatan edukasi kesehatan yang diberikan efektif dalam meningkatkan pengetahuan, sikap dan efikasi diri peserta.

Tabel 2.

Perbedaan Skor Pengetahuan, Sikap dan Efikasi Diri Sebelum dan Sesudah Edukasi

\begin{tabular}{lcccc}
\hline \multicolumn{1}{c}{ Variabel } & Mean \pm SD & SE & Pvalue & N \\
\hline Pengetahuan & & & & \\
Sebelum & $12,18 \pm 4.69$ & 0.82 & 0.000 & 33 \\
Sesudah & $17,54 \pm 3.77$ & 0.65 & & 33 \\
\hline Sikap & & & & \\
Sebelum & $36.21 \pm 4.94$ & 0.86 & 0.000 & 33 \\
Sesudah & $46.60 \pm 4.02$ & 0.70 & & 33 \\
\hline Efikasi diri & & & & \\
Sebelum & $20.97 \pm 3.55$ & 0.62 & 0.000 & 33 \\
Sesudah & $24.57 \pm 0.87$ & 0.15 & & 33 \\
\hline
\end{tabular}

Edukasi gizi sering dipergunakan sebagai alat untuk meningkatkan tingkat pengetahuan, sikap dan perilaku sasarannya. Salah satu studi yang dilakukan Silalahi et.al. tahun 2016 di (Silalahi et al., 2016)

\section{SIMPULAN DAN REKOMENDASI}

Pelaksanaan edukasi kesehatan pada orang tua dan guru santri Madrasah Mumtaza Isamic School merupakan bentuk pengabdian masyarakat dosen Program Studi Sarjana Kesehatan Masyarakat Universitas Pembangunan Nasional Veteran Jakarta. Berdasarkan wawancara dengan perwakilan persatuan orang tua dan guru didapatkan informasi makin muda nya usia menarche santri, sehingga diperlukan edukasi kesehatan tentang kespro termasuk masalah anemia pada santri. Kegiatan ini bertujuan meningkatkan pengetahuan, sikap dan efikasi diri orang tua dan guru santri madrasah Mumtaza Islamic School dalam berperan sebagai motivator para santri mengonsumsi TTD dan meningkatkan asupan makanan sumber zat besi. Hasil evaluasi menunjukkan adanya perbedaan signifikan antara pengetahuan, sikap dan efikasi diir sebelum edukasi dengan setelah diberikan edukasi.Harapan guru dan orang tua santri kegiatan serupa dapat dilakukan secara periodik.

\section{REFERENSI}

1. Aditianti; Yurista,Permanasari; Elisa, D. J. (2015). Pendampingan minum tablet tambah darah dapat meningkatkan kepatuhan konsumsi TTD pada ibu hamil anemia. Penelitian Gizi Dan Makanan, 38(1), 71-78. 
2. Apriningsih, A., Madanijah, S., Dwiriani, C. M., \& Kolopaking, R. (2019). Peranan Orang-Tua Dalam Meningkatkan Kepatuhan Siswi Minum Tablet Zat Besi Folat Di Kota-Depok. Gizi Indonesia, 42(2), 71. https://doi.org/10.36457/gizindo.v42i2.459

3. Apriningsih, Madanijah, S., Dwiriani, C. M., \& Kolopaking, R. (2020). Determinant of highschool girl adolescent'adherence to consume iron folic acid supplementation in Kota Depok. Journal of Nutritional Science and Vitaminology, 66, S369-S375. https://doi.org/10.3177/jnsv.66.S369

4. Contento, I. R. (2011). Nutrition Education.Linking Research, Theory and Practice (S. L. B. H. S. N. Goldberg (ed.); 2nd editio). Jones and Bartlett Publisher.

5. Kemenkes. (2016). Pedoman pencegahan dan penanggulanngan anemia pada remaja putri dan wanita usia subur (WUS).

6. Kementerian Kesehatan Republik Indonesia, Rencana Strategis Kementerian Kesehatan Tahun Rencana Strategis Kementerian Kesehatan Tahun 248 (2015). https://doi.org/351.077 Ind r

7. Ministry of Health RI;Kementerian Kesehatan RI Badan Penelitian dan Pengembangan Kesehatan. (2019). Laporan Nasional RISKESDAS 2018.

8. Silalahi, V., Aritonang, E., \& Ashar, T. (2016). Potensi Pendidikan Gizi Dalam Meningkatkan Asupan Gizi Pada Remaja Putri Yang Anemia Di Kota Medan. Jurnal Kesehatan Masyarakat, 11(2), 295. https://doi.org/10.15294/kemas.v11i2.4113 